\title{
Editorial:
}

\section{The Second Dimension in Art}

\author{
Tirtha Prasad Mukhopadhyay \\ chiefeditor@rupkatha.com
}

The question of art in the context of the more general concept of creativity has to be addressed from the foundations of science. The subjective notion of creativity, which still persists in the humanist attitude to things, has to be resolved and broken, indeed abrogated as it were, as an infantilic, or exilic dream. Admittedly the idea of a creative generator ensconced in the human soul does not stand the test of empirical query. It may turn out to be true if possibilities of other dimensions of resources and energy were assumed to be true - the question whether a "spirit"like medium is part of the dynamics (as the ancients had suggested) is one which may not be yet encompassed by the perceptual instruments available to science. It is difficult to visualize gravity as described in the physics of relativity for example - for which there is a mathematical model, already in place in the hypothesized model of the "curvature of space" for example. Einstein's explanation of gravity could be encountered as a mathematical possibility, although as easily as a tangible working mechanism.

For the arts empirical analysis is headed in two directions. One is titled ambitiously, as neuroaesthetics, and the other broader term involves studies on the psychology of what is called creativity - or in short "creativity studies", which is again a broader rubric for studies on a greater variety of design and creative pursuits, and activities for the contemporary industry. Semantically, again the term 'innovation' is used more loosely with science and technological creativity or design. But these were very relevant issues to my enquiries as a student of the arts, and since an artist or designer, when one makes this choice, of wanting to create something 'artistic', under the social precepts of the genre and given one's temperament - one already proposes a trajectory for oneself, that is one's life and career, in an unremitting passion for designing something novel and unique - a desire to express oneself, to make the object of expression better and more perfect following an insatiable commitment that consumes everything else, like a fire, autonomous and ungovernable as it would seem. If there is ever a model of an artist's autobiographical reflection for one's personal diary then these would be the problems one had to face and understand. Creativity or art is no longer therefore assumed to have its origins in a story - because the priorities and contexts for an investigation have changed. The creative process is a function of the behaviorally engaging hominid, just as there is improvisatory behavior in other species in different chains of mutation. The animal sensitivity to the crude and enormous expanse of landscapes, the ocean, the rugged terrain of mountains, canyons, gorges, and then towards food, and shelter - and toward moments on a social frame, or toward emerging technological urbanscapes, or interplanetary vistas.

From a behavioralist perspective there was perhaps only one reference that finally seemed to me to be more pertinent for understanding the creative process. Since creative life seemed to be a full reflection of a total mental-physiological reflex system to tasks at first the Aristotelian

(c) AesthetixMS 2016. This Open Access article is published under a Creative Commons Attribution Non-Commercial 4.0 International License (http://creativecommons.org/licenses/by-nc/4.o/), which permits non-commercial re-use, distribution, and reproduction in any medium, provided the original work is properly cited. For citation use the DOI. For commercial re-use, please contact editor@rupkatha.com. 
term "praxis" appeared to me to be rather inclusive and comprehensive - as it indicated a broad overall attitude or tendency in the life of an artist. There are no long term goals that describe a creative project; although some aspects of Erikson's developmental psychology recognizes this life-long engagement behaviors in a post adolescent contexts. The creative individual would adopt this pragmatic approach in the obsessions of a life-time. In fact the classical term "praxis" - I discovered - was ensconced in a Greek phrase praxis teleia (Gilbert Murray 1956). So what Aristotle means is that creative arts are fostered with practice, which is aimed with a telos or sense of an end -which suggests perfection, the true mark of the arts. Indeed Murray points out in his commentary on the Poetics there is a need to merge praxis with a more difficult, non-temporal concept of energeia or soul-drive. Behavioral creativity could be understood as praxis, which implies performing repetitive actions that could integrate the different classes of actions that carried formative sentiments in the components of their media. Finally praxis would be a state of performances in which the created objects would elicit pleasure. Therefore to confer on this sense of creativity we would have to refer to this Aristotelian element of praxis teleia or energeia but only in an empirical sense- since it does justice not just to art, but to the belief system involving a faith or hope in a an aesthetically satisfactory life. Creativity also inspires every aspect of life and its actions (as is said in Nichomachean Ethics for example)- of a moral as well as intellectual type, and is integral to what is metaphorically a journey of a souls - as would be defined by its energeia. Behaviorally as well 'creativity' implicates the whole of an individual, and seeks to define the outer limits of one's efforts, of trying to elicit a more felicitous experience in things. Perhaps something of a synoptic bur discreet list of the tendencies present in creative tasks helps us better understand what goes on through the creative life, and with Guilford's (1950) description of this larger system of creativity - and then Torrance'e attempts to quantify creative output on a psychometric scale came out a change in our view of creativity - which became mathematical, quantitative idea of innovative tasks (Torrance 1963; 1988). I refer to the notion of praxis since it best describes the scientific temperament for understanding one such basic instinct as creativity.

Again, that creativity has not been amenable to a good definition in modern neuroscience points to an important factor in recognizing the trajectory of the process. So why praxis - in this context. Because praxis refers to 'doing' or task execution of some sort -but this is exactly the empirical - or more specifically the behavioral quality of creative pursuits that are discussed in Guilford (1950), Torrance (1963) and Amabile (Amabile 1966). When Aristotle already defined praxis in Poetics, and in Book II of Nichomachean Ethics he was recognizing the contextual fruition of the human instinct to act in a creative way. I would say that praxis clarifies the nonsubjectivist understanding of creativity and design innovation that has been appropriated for our contemporary pursuits of art and design -- this is one common ground between classicism and empirical neuroaesthetics that I found, like the ground beneath one's feet (for aesthetes still being groomed in a humanist tradition in the last decades of the twentieth century). But the problem of creativity was important because any effort to resolve the process down to its neurobehavioral components meant that we could apply to test and reinforce training for it, or eliciting guidelines for what Guilford called "divergent thinking”.

Indeed creative life composits its own search and destiny for itself; as such it has no use except to be available like a working manual - I shall briefly describe how one could be lead to the analytical part of the creative process. There is no explanation however for the compelling energy which drives creative people - ones who are now thought of as having a larger range of resources in terms of the choices available to them and their willingness to experiment with newer designs, and adopt newer formats. The only ground on which we find a semblance of the old perception 
of creativity as a kind of subjectively realised drive - is when, as Murray (way back in the middle of the last century) was saying with a faint classical suggestion that praxis could be incorporated with energeia - perhaps with reference to energeia as a tendency, with that sense of immanence that drives humans, and promotes innovations, both technological and ideational - and leads to the phases of transformative social life, and determines much of the way the belief system is absorbed and adapted to the needs of a renewed, and superior livelihood.

This practical or pragmatic energy of creativity may have been once assumed to have been this force capable of impelling an individual, and this is perhaps more in singular conformity with observed facts of life. The creative person has an energy-level and a strange obsession with tasks involving problem-solving strategies and - as modern behavioralists would like to believe, a tendency to re-adapt to priorities, in their attempt to revisit moments of heightened flow in executing and reinstating the design. Among other things behavioralism is the best option that we have in the context of the state-of-art of thinking about these formative aspects of life.

The journey of placing art in this empirical context - for me - began with the need first to understand the frame of visual art. The quest stood against the received discourse - but a longer period of contemplation guided me to believe that there was something unique about the arts. This included the visual arts, theater, music - although I had not yet deeply started thinking about it, and revision of issues set me on a trail. I felt I discovered something - and I wanted to find proof for it. This was a difficult task, given my physical conditions but the battle is also perhaps the same for everyone. I could objectify this discovery in terms of images - a few of these I shall show here. Discovery is culmination of a search, and for this project which I began it all started taking shape quite early - but I started articulating it once I got involved in my research the first time I came to the America. One aspect of this search of mine has taken shape entirely on this new continent, and its bearings are with me. Creativity, in the visual realm generates interesting results, and are not delimited by time or space - but ever accessible to the mind of the artist. In visual arts praxis - the limits are offset by the satisfaction derived from the continuous transmutation of frames and - the scientific resolution of imagery. Much hair has been split in the cognitive sciences regarding this discovery. What does the visual image represent - the acknowledgement that the visual image, whether it is in its two dimensional or three dimensional manifest, could correspond to a recognizable object in the world. Gibson had made this claim in the seventies- I felt that the artistic image, like that of a portrait of a face seen from an angle - or the shape of the body, or even any optical symbol seemed - in several instances to gain a character or a special quality.

If Gibson's and Neisser's study of the image were revealing of the spatial correspondences the research in cognitive science was no more than mute, if not oblivious, of the positive mental stress provoked by the artistic image. The paradox is that creativity here stands in need of an emotive component - and this research had been lacking.

A project developed from a humble University Grants Commission fund in India gave me this impetus to explore the emotive processing component of art and creativity - the fun element that is so crucial for survival and progress. The opportunity then was to tell others that there was this strange quality in the more artistic or crafted images - earlier I was groping around for a term. It seemed to me fit to call this property of the visual image "miniaturization", in the absence of any word which to my mind could explain the process. What are the cognitive networks responsible for this kind of evocation? He had produced a photo and then asked me if I knew that this BW picture was in fact used by Cezanne to create a portrait. Because painting takes these visual cues and transmutes them into a stylized and textured format - here to me was a basis of all 
the visual arts, but more so the secret that explains the trajectory of creativity in its most elusive and precious manifest. The photograph was that of an Old Lady with a Rosary

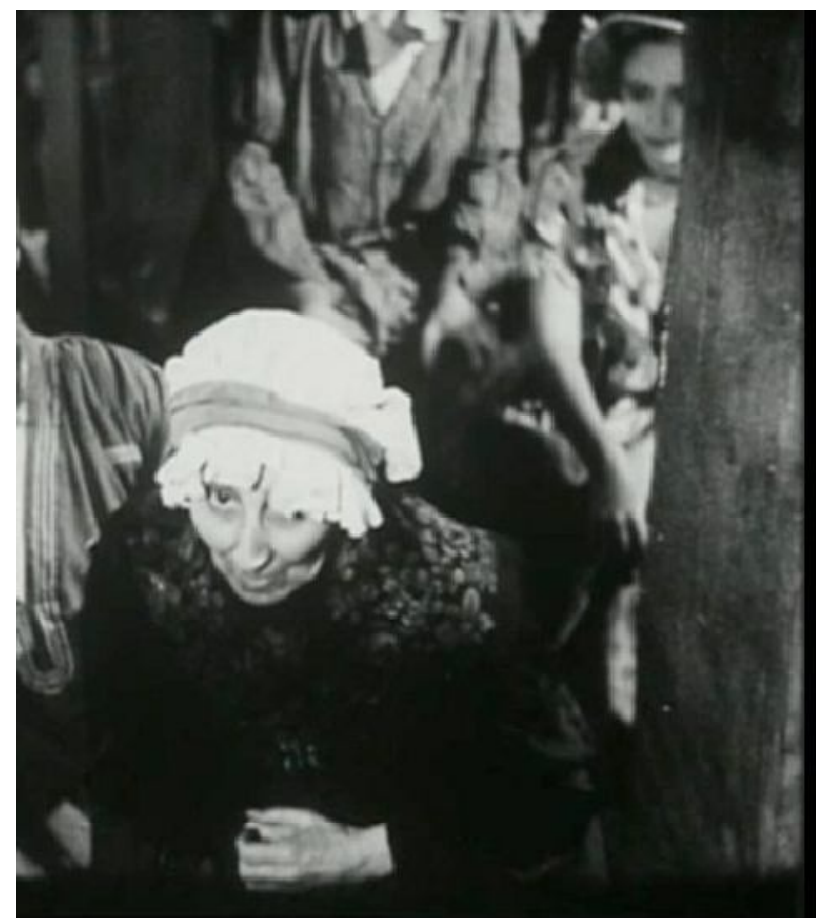

Figure 1. Photograph original for Old Lady with a Rosary

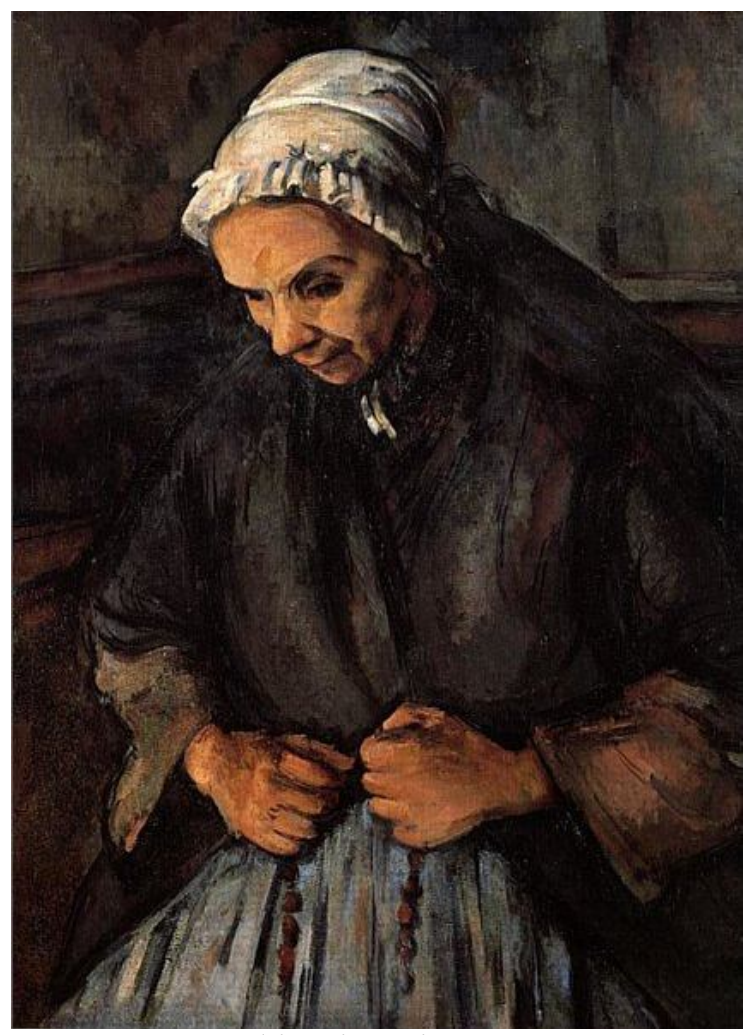

Figure 2. Old Lady with a Rosary 
$v \mid$ The Second Dimension in Art

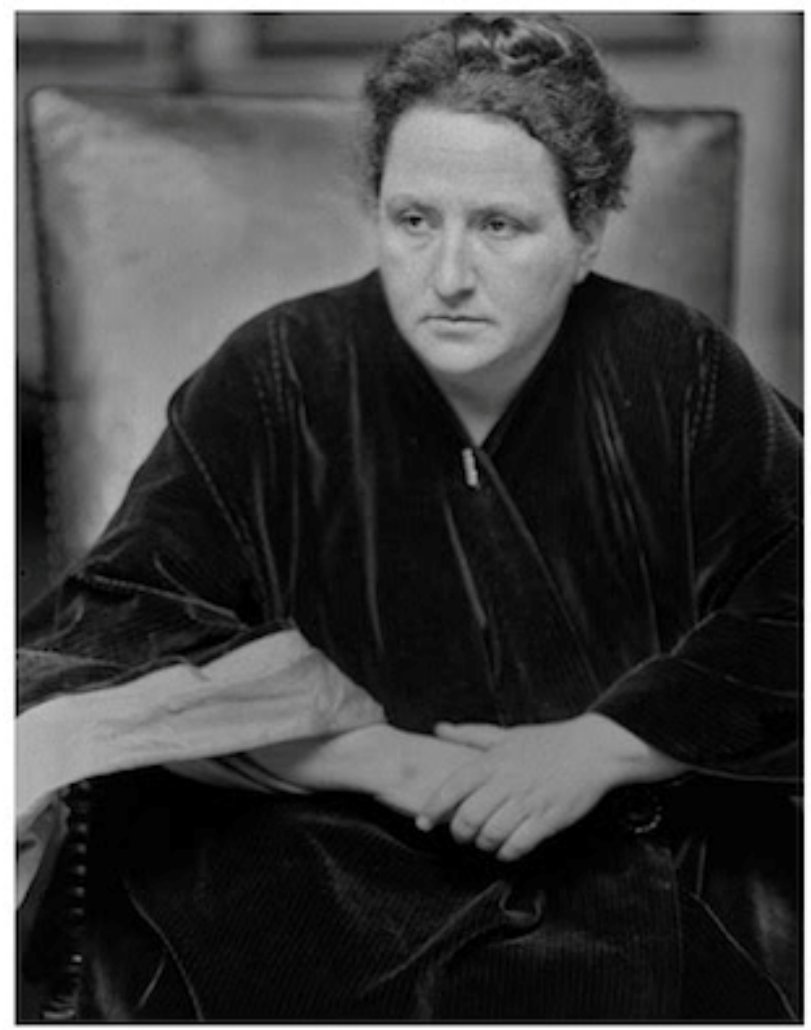

Figure 3. Photograph of Gertrude Stein

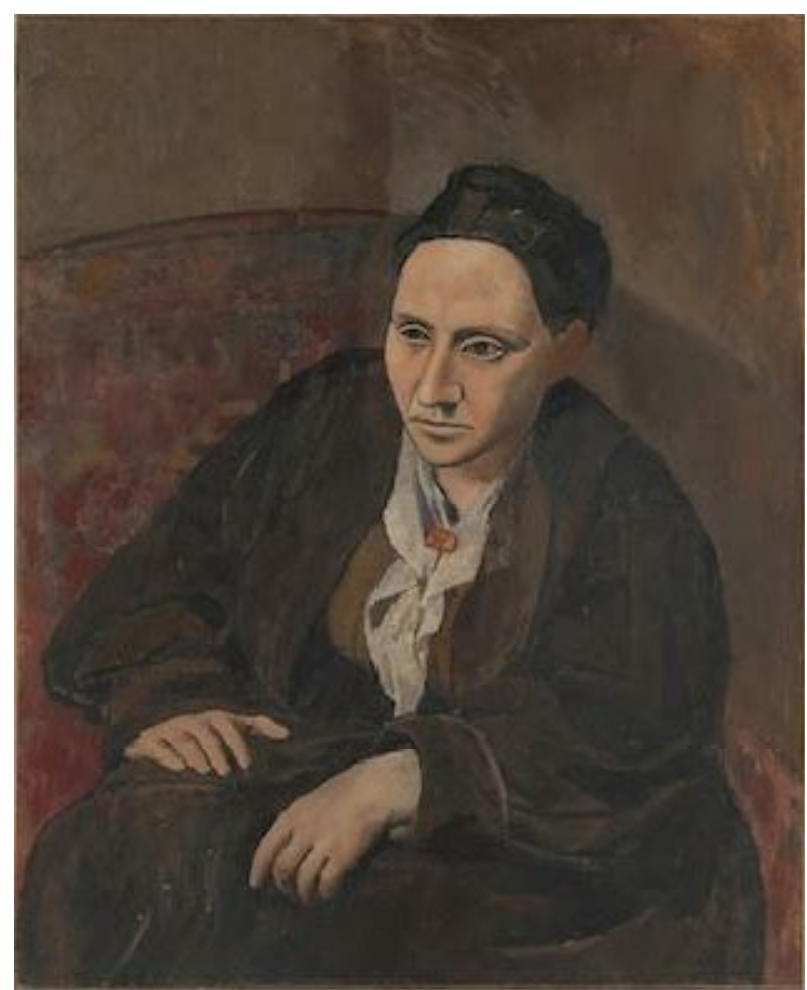

Figure 4. Picasso Portrait of Gertrude Stein 


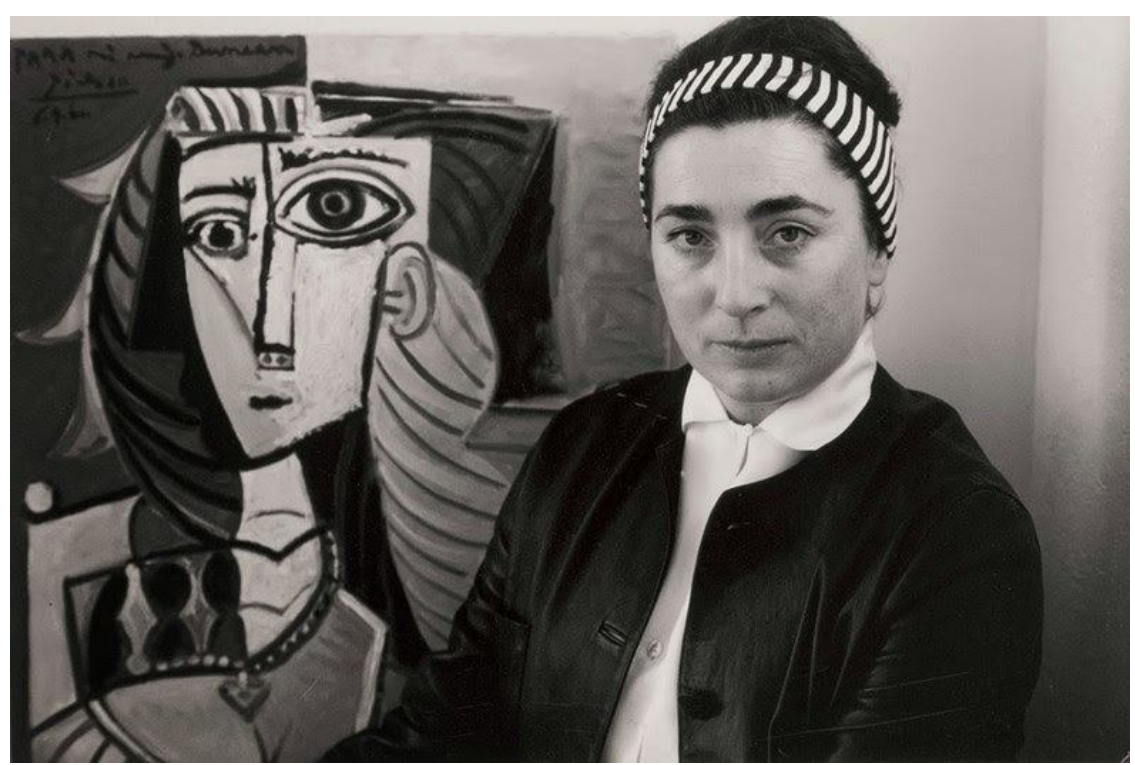

Figure 5. Portrait of Jaqueline Roque
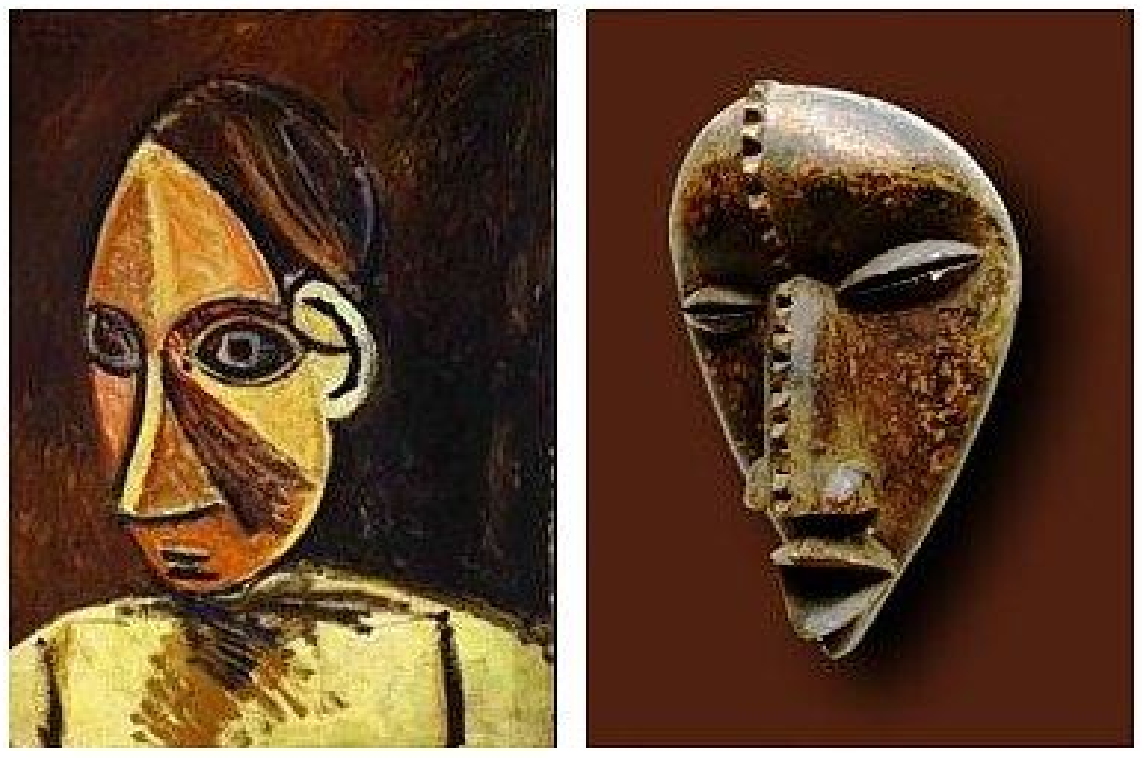

Figure 6. Portrait of a Woman 1907, Mask.

In all of these images what was mainly happening was -stylization. Looking intently upon this image reveals or carries us to a second dimension of visuality, a dimension marking a qualitative disjunction. We could re-frame the question this way that the cognitive invariants of the images are similar - in the more realistic impressions the parallels are visible, we do not fail to recognize the person in question. But unlike Renaissance portraits, the simulations of Holbein for example, the distracted innovativeness of such renderings are stupendous examples of divergent creativity. The creative energy is manifest in the vitality with which the art is made not to resemble the source, or the photograph but because of the ability of the artist to incorporate cognitive stimuli that only retains a limited amount of semblance and a greater freedom in divergence. 
This liberation of the anxiety that the image represses creates the new image of the artist, If the origin of creativity takes for its departure the saddened and incommodious space of existence then the vision of the artist now creates a separate or 'demarcated' plane of perception. This to my mind is an important discovery - not because it may have the potential of catching something in the cognitive process that has not been identified with the degree of clarity that it deserves, but also because it fits in with the indices of what I held on were the best precepts of aesthetic creativity - this principle had to be registered and examined but also verified for extreme cases of divergence in creative design, and especially for non-events, which invited new opportunities in closet anthropology. The re-alteration of visual cues is not an easy task: it could only be successfully achieved with praxis, and re-arrangement of stimulus. The cognitive process that elicits such information for the visual system is also worth studying, although this could make us drift outward in uncharted maps of the brain.

Even if we had to preserve this sanctuary of ideas for the visual image we could then explore the other boundaries of creativity In fact the visual system was just one of the means of doing thiscreative transmutation builds outlines of creative tasks, the lineaments which are meant to dissolve and the superstructures that are supposed to rise. The debris of things resurrects things to come in all the arts, music, digital realities, and technological posthumanism. This brief essay would show us why this process is important for the cognitive system - the suspected presence of an over-arching cognitive 'process' may be a reality, although any amount of research to show that there is a master-plan for a neural process that generates or evokes creative divergence now could only fall too short of being satisfactory; because of the enormous amount of data involved and the unknown functions within brain areas and the the dimension of networking involved that this search under the instruments and capabiities of integration that we have on a conscious level is only a distant dream. This secret once uncovered might enlighten us on the road toward machine intelligence and independent autonomous creators.

The discovery of this premise in visual innovations should indicate something more precise - in response to the question elicited in the section on alteration of visual invariants by the artist and the penetration into a second dimension of effects. The 'secret' could be found in another approach to the creativity question - which I felt again only helped in comprehending how creative precepts are born and what are the elements responsible for their attractiveness.

\section{Emotions}

The transmuted image created an opportunity for me to understand what this other dimensionality might be like. Visual art crystallises a graph of a feeling through a synoptical, and totemic externalization of the subjects of representation - including in such contemporary art pieces as in the weird bionic insects designed by robotic artists from San Miguel de Allende - in the machinic caricature. In the juxtaposition of the comic and non-deleteriously happy perspective of everything that seems so predictable and clever in real life - there is the same reduction, or miniaturization at work. Miniaturization is just a visual aspect however because these artworks - like the paintings we discussed - were stylized miniatures - we could also call them "aggrandizements" depending on the components of the image that we choose to look at. In Cezanne's Woman with the Rosary, Picasso's Masks, and the great musical contrapuntal suggestions of Mozart, and Nam Jun Paik's $K-456$ robotic installation - there is an undiminishing humor that redeems the past and resurrects the dead original or model to life. The interest that creative transformation generates is not attained with disposition, or disruption of expectations in gesticulation - perhaps it might involve simulation of a physical action, what is of essence here is emotion. The way a space-time module is reduced in creative production -that is stylized, miniaturised or aggrandized just as features miniaturized or aggrandized together -as in a binary 
recombination (we do not know if a formula exists) but in general the bipolarity of juxtaposed components only accentuates certain unexpected reflexes in our sensory packet. This is the reason behind the emotional focus that determines the artistic image - in fact for me 'divergence' represents this cognitive-emotive shift from one level of sensoriality to another level of heightened or attentive, sometimes singularly emotive transition. If we are to include the wider rubric of creativity for the wider ambit of non-art species, like technological innovation, design, or consumer outreach - and then machine design or architecture, and then virtual reality, (which are not -strictly speaking - spatially located but only perceptual cues and more radically divergent dispositions, then creativity still consists of this peculiar emotive evocation of an antecedent. How does the effect come about - in what angles of reception or appropriation does this work - perhaps the neural correlates are multinodal: indeed all experiments tend to show that an emotively symbolic visual pattern would involve an affectation of pre-frontal cortex just as much as as it would invite the norepinephrine and dopamine transmitters to generate effects. The cerebral process is at this stage beyond the purview, and indeed not much research on what Oshin Vartanian called neuroaesthetics discusses emotive resources of the arts. Probably in neuroaesthetics -as much as in more specific instances of research on this creative process there first needs to be an acknowledgement of this enfocussed miniature that evolves as a result creative practice.

Hereby I am perhaps coming close to take a call - creativity has hardly anything to do with non-emotive evocation even though non-emotive creativity may still qualify as a type of divergence. In twenty years of research by Guilford however we don not have any evidence of likening the emotive structure of divergence to the creativity question - in an earlier generation of Western criticism there was greater sanity in the acknowledgement of, I believe, what plausibly exists, the "demarcative" mental state of emotions. But demarcative may be problematic. Though creativity results in emotive conditions or reflexes these are not essentially different but may merely represent intensities on a spectrum. This is a view to which I am more strongly inclined under present states of enquiry -hints of which arise in the research on what modern cognitive studies refer to as valence states - rather than emotion alone. Such dichotomies do not exist in the art experience -even though they do so in analytical treatment of issues of creativity. So creativity

a. Involves emotive circuits and reflexes

b. Art objects provoke valence intensity for a positive state of emotions

c. Creativity leads to automatism -

These are some of the problems in aesthetics -a description or psychometric analysis of such emotions may help us in defining a better trajectory for wellbeing and social progress - it could also have therapeutic potential for a good deal of manic-depressive states. These are some of the other issues that we need to explore. 